\title{
NOVAS COMUNIDADES CATÓLICAS OU CRISE DO SISTEMA PAROQUIAL?
}

\author{
Prof. Dr. Leonildo Silveira Campos
}

Novas Comunidades Católicas, organizado por Brenda Carranza, Cecília Mariz e Marcelo Camurça, reúne 12 autores em torno de um fenômeno que atinge a pastoral da Igreja Católica e as maneiras de seus fiéis vivenciarem a religião na vida cotidiana, afetando a forma tradicional de se desenhar a dimensão organizacional da Igreja. Que rupturas estão ocorrendo e que continuidades podem existir nesse contexto de rápidas e profundas mudanças no cenário religioso? Que relação há entre as "novas comunidades" e os "novos tempos"? Que implicações tais transformações trazem para a Igreja em sua missão, catequese, liturgia, pastoral e arranjos institucionais?

Os artigos estão divididos em dois blocos: "A RCC: Entre a tradição e a modernidade" e "Novas comunidades, novos estilos de vida na (pós-)modernidade". No primeiro, cinco textos tomam como objeto a Renovação Carismática Católica, fenômeno situado "entre a tradição e a modernidade". No primeiro, Luiz Roberto Benedetti sugere que há novos rumos para o catolicismo. No seguinte, Brenda Carranza aponta para um deles: a "pentecostalização católica". Marcelo Camurça, no terceiro capítulo, analisa o surgimento de um catolicismo midiático. O quarto, de Carlos Eduardo Procópio, aborda o esforço da RCC de escolher o ambiente universitário como um campo missionário.

No fim do bloco, Emerson José Sena da Silveira parte de uma leitura de Tarô dos Santos, escrito por Robert M. Place, para mostrar como algumas mudanças levam a religiosidade católica para caminhos distanciados do controle da instituição, surgindo daí um catolicismo eivado de traços típicos de uma religiosidade estilo New Age. Silveira usa o conceito de hibridismo e de ressurgência da religião em um novo contexto cultural.

No segundo bloco encontramos artigos que tratam de questões como: Por que novas comunidades católicas crescem? Como se combina o velho (medieval) e o novo? Que novidades comunidades como "Canção Nova", no Brasil, e "Shalon", em Portugal, trazem para o debate acadêmico? Que papel a devoção mariana desempenha nesse processo de "reformatação" do catolicismo em tempos de (pós-)modernidade? 
O sexto capítulo, escrito por Carranza e Mariz, tem por título "Novas comunidades católicas: por que crescem?". Logo depois, "Medievais e pós-modernos: a Toca de Assis e as novas sensibilidades católicas juvenis", por Rodrigo Portella, toca em outro ponto, também significativo, que é a convivência dos antigos traços medievais com as aspirações juvenis. Os dois capítulos seguintes tematizam a "Canção Nova".

No capítulo oitavo, Eliane Oliveira analisa o impacto do conceito "a vida no Espírito" na origem, desenvolvimento e expansão da "Canção Nova". Esse movimento se expressa tanto em comunidades virtuais na televisão e na Internet, como também em comunidades locais onde há retiros, orações, curas, e prodígios.

O capítulo nono, de Eduardo Gabriel, volta à brasileira Canção Nova para analisar a transnacionalização do movimento que, ao chegar a Portugal, criou conflitos, questionamentos e problemas com a hierarquia religiosa católica. Gabriel observa bem que o mesmo fenômeno tem ocorrido com o neopentecostalismo brasileiro, que não encontrou na Europa um espaço religioso vazio. Talvez por ser "novo" e trazer "novidades", provoca mal estar no campo já existente.

O décimo capítulo, "Shalom: construção social da experiência vocacional", de Cecília Mariz e Luciana Aguillar, pensa o caso da Comunidade Católica Shalom, fundada em Fortaleza, em 1982. Com aguçado senso missionário, o grupo possui hoje 12 casas no exterior, do total de 57 . Seus membros apresentam forte sentimento de vocação divina para uma vida comunitária, de espiritualidade e intimidade com Deus.

O último capítulo aprofunda a devoção mariana, vista como fundamental na Renovação Carismática Católica. Nessa religiosidade o papel reservado a Maria, mãe de Jesus, assim como o apego à Eucaristia e à fidelidade ao Papa, se tornaram traços característicos que garantem as fronteiras entre a "pentecostalização católica" e a protestante. A importância de Maria tem muito a ver com as lutas feministas na maioria das igrejas cristãs, que, a despeito do avanço, ainda encontram dificuldades no relacionamento com as hierarquias, predominantemente masculinas.

O livro reúne estimulantes contribuições de especialistas em ciências sociais e religião para o estudo do catolicismo nestes tempos de "Idade Mídia". A obra atesta o dinâmico e rápido processo de reconfiguração que o catolicismo está experimentando desde as últimas décadas do século XX. Acreditamos que as forças desencadeadoras dessas mudanças são inicialmente externas ao campo religioso. Porém, essa recomposição do cristianismo acontece em um contexto de secularização, concorrência e pluralismo Os textos estimulam perguntas: Até que ponto o cenário religioso, continuamente redesenhado no Brasil desde a segunda metade do século XIX, se exterioriza em novas expressões grupais, comunitárias e midiáticas da fé católica apostólica romana? O que há de novo no aparecimento de novas comunidades católicas em um cenário onde, até poucas décadas, a novidade que parecia se perenizar eram as Comunidades Eclesiais de Base? O que está provocando o aparecimento de 
comunidades resultantes tanto de movimentos de feições conservadoras, como Opus Dei, quanto de outros, que nem sempre cabem em rótulos elásticos como New Age ou da Renovação Carismática Católica? Que rupturas ou continuidades tais comunidades apresentam em relação à tradição católica acumulada há séculos, especialmente na América Latina e Europa?

A coletânea estimula estudos a respeito da dinâmica religiosa católica visível no acelerado trânsito religioso no País no decorrer da última metade do século XX. O IBGE apontou uma queda no número de católicos, de 93,7\% em 1950 para 73,9\% em 2000, enquanto os "evangélicos" (outra categoria elástica) passaram de 2,6\% para $15,6 \%$ da população no mesmo período. Enquanto isso, o Brasil, que era um País rural, se tornou urbano. Em 1950 somente 36,1\% dos brasileiros viviam em cidades, enquanto em 2000 a taxa de urbanização era de $81,2 \%$. Tais mudanças levaram a uma busca por novas formas de ancoragem da tradição cultural e religiosa. Enquanto isso, houve a modernização dos meios de comunicação de massa (imprensa, rádio, televisão e internet).

É claro que todas essas mudanças não apanharam de surpresa os setores mais intelectualizados da Igreja Católica, que sempre estiveram atentos e têm usado pesquisas em sociologia religiosa para entender o país. Também a partir delas, o Centro de Estatística Religiosa e Investigações Sociais (CERIS) tem mapeado e proposto ações pastorais. Por exemplo, em 1967, logo após o Concílio Vaticano II, um simpósio coordenado pelo padre Affonso Felippe Gregory enfrentou o tema "A paróquia ontem, hoje e amanhã" (Vozes 1967). Nos textos das palestras, inclusive de Joseph Comblin, aparecem, ao lado de constatações otimistas com a "renovação paroquial", preocupações pós-conciliares com crescentes sinais de uma crise no sistema paroquial. A RCC apenas começava nos EUA e as CEBs ainda engatinhavam. Já em 2002, organizado por Luis Alberto Gómez de Souza e Silvia Regina Alves Fernandes, publicou-se o texto Desafios do catolicismo na cidade: Pesquisa em regiões metropolitanas brasileiras (Paulus 2002). Nessa pesquisa pesou a expressão "catolicismo em tempos de transição", que orientou o levantamento de dados sobre o trânsito religioso.

A Igreja procurou responder, em especial a partir da 2 $\underline{\underline{a}}$ Guerra Mundial, ao desmanche das formas tradicionais de atuação, desencadeando movimentos pautados na Ação Católica, destinados a cooptar jovens (JAC, JEC, JOC e JUC) e operários para as causas da Igreja. No decorrer da ditadura militar (1964-1985), movimentos católicos surgiram entre estudantes, operários, camponeses e políticos na luta pela anistia, direitos humanos e melhoria das condições de vida nas cidades.

Houve, num período de quatro décadas, significativo aumento no número de paróquias, que passaram de 4.764 em 1965 a 9.410 em 2005, de acordo com dados do CERIS. Esse crescimento foi de 97,52\%, enquanto decrescia o número de católicos. Em outras palavras, o número de paróquias aumentou enquanto pipocavam por todos os lados novas formas de manifestação de afiliação religiosa. Será que a Igreja não esteve insistindo em um modelo pastoral e administrativo que não mais oferecia 
bons resultados? A explosão de novas comunidades católicas parece responder às crescentes dificuldades de manter a fé católica fundamentada nas estruturas visíveis da Igreja em uma sociedade urbana, em que a mídia passou a ocupar um importante lugar no processo de recomposição do religioso. São esses novos tempos propícios para o surgimento de "paróquias" e "dioceses" virtuais?

Tais números têm preocupado pesquisadores, estrategistas e figuras importantes do clero católico brasileiro, para não dizer do próprio Vaticano. Também, esses dados indicam a ocorrência de um nomadismo geográfico e social expresso num trânsito religioso que afeta não somente a Igreja Católica, como também as denominações protestantes tradicionais (luteranos, metodistas, presbiterianos, congregacionais, batistas e outros).

Por outro lado, em uma sociedade em que os números definem não somente a quantidade, mas a essência e qualidade das coisas, o decréscimo de uns e aumento de outros grupos religiosos se tornou uma questão de sobrevivência para os considerados "perdedores". Os pentecostais, os da Renovação Carismática Católica e os "sem religião" foram os maiores beneficiários desse processo de diversidade e de pluralismo. No dizer de Daniele Hervieu-Léger (O peregrino e o convertido. Lisboa: Gradiva 2005), essa movimentação da religião está associada às figuras do "peregrino" e do "convertido". Como entender a reconfiguração do campo religioso, na melhor das hipóteses, ou o seu desmantelamento, na pior delas?

Segundo uns, as causas de tantas mudanças podem estar na modernidade; segundo outros, na pós-modernidade. Na identificação desses motivos estão também discussões sobre o processo de secularização ou de dessecularização. De qualquer maneira, está em operação um amplo "desmanche" dos arranjos tradicionais que marcavam, inclusive, a construção da identidade e do relacionamento entre as instituições religiosas e os grupos brasileiros. Assim, ocorreu um deslocamento das instituições e dos atores que fazem da religião o ganha pão ou que a elas se dedicam em tempo integral. Enfim, tudo o que parecia estar solidamente instalado se torna "líquido" ou se "decompõe" em pleno ar. Os limites territoriais ou físicos do sistema paroquial não poderiam passar sem arranhões nessa severa recomposição do catolicismo.

Pressupomos haver uma profunda crise no sistema paroquial católico-romano. Há uma situação de mal estar na forma tradicional de ação da Igreja Católica nas cidades - o sistema paroquial. Estabelecido na Europa do final do primeiro milênio da Era cristã, o sistema paroquial nunca foi a única maneira de a Igreja marcar presença na vida cotidiana das pessoas. Sempre existiram outras formas comunitárias de manifestação da fé católica nos monastérios e ordens religiosas. De semelhante modo, nos meios protestantes surgiram, no século passado, "movimentos paraeclesiásticos", que atuam à margem da Igreja-situada-no-local-de-residência dos fiéis, sem contar "novos ministérios" entre os pentecostais.

Nesse sentido, o deslocamento interno provocado pelas mudanças culturais da 
"rapidação" da modernidade não atingiu diretamente uma Instituição estática ou fixada de uma vez para sempre no sistema paroquial. Muito pelo contrário, o campo religioso sempre esteve em movimento. $\mathrm{O}$ seu dinamismo, que pode ser descrito a partir da teoria sociológica de Pierre Bourdieu, nunca deixou de colocar em relações assimétricas atores diversos como leigos, profetas, sacerdotes e mágicos. Tais relações conflitivas também fazem parte do cenário que está sendo desenhado pelas novas comunidades católicas.

Por isso Novas Comunidades Católicas traz estimulantes observações e pistas para a continuação de pesquisas a respeito da "nova" face do "velho" catolicismo, tratando de suas novas formas de visibilidade social e cultural no país, presentes nas novas comunidades católicas - especialmente nas virtuais - de corte carismático. Por esse e outros motivos, recomendamo-lo aos leitores interessados no estudo do fenômeno religioso no Brasil.

Carecemos, porém, de novas pesquisas, pois há outras reações católicas à modernidade e à secularização, que são comunidades de corte mais integrista ou conservadoras, entre as quais podemos citar: Folcolares, Tradição, Família e Propriedade ou mesmo Opus Dei. Até que ponto as CEBs também não representaram uma acomodação da Igreja aos mesmos desafios?

Completaria a coletânea um capítulo que analisasse o surgimento de novos intermediários culturais, de lideranças que animam essas e outras "novas comunidades". Observemos que os animadores das celebrações católicas se desconectam progressivamente da figura tradicional do clero e dos especialistas religiosos. A missa é vista nesse contexto como um "show-missa" e os celebrantes são os "padres-cantores". O despreparo da maioria desses especialistas para atuar no novo "espaço pós-moderno" parece tornar necessárias mudanças na educação teológica dos futuros atores religiosos. Estamos ou não diante de uma crise do sistema paroquial católico?

Leonildo Campos (leocamps@uol.com.br)

Professor titular da Universidade Metodista de São Paulo, Faculdade de Humanidades e Direito, lecionando no Programa de Pós-Graduação em Ciências da Religião, e como professor convidado, na Faculdade de Teologia de São Paulo da Igreja Presbiteriana Independente do Brasil. 